Nigerian Journal of Technology (NIJOTECH)

Vol. 39, No. 2, April 2020, pp. 369 - 378 Copyright@ Faculty of Engineering, University of Nigeria, Nsukka, Print ISSN: 0331-8443, Electronic ISSN: 2467-8821 www.nijotech.com http://dx.doi.org/10.4314/njt.v39i2.7

\title{
ADSORPTION BEHAVIOR AND CORROSION RATE MODEL OF SODIUM CARBOXYMETHYL CELLULOSE (NA-CMC) POLYMER ON ALUMINIUM IN HCL SOLUTION
}

\author{
O. M. Egbuhuzor ${ }^{1, *}$, I. C. Madufor ${ }^{2}$, S. C. Nwanonenyi ${ }^{3}$ and J. O. Bokolo ${ }^{4}$ \\ 1, 4, PROCESS LABORATORY, DEPARTMENT OF AGRIC \& BIORESOURCES ENGINEERING, UNIVERSITY OF NIGERIA \\ NSUKKA, ENUGU STATE, NIGERIA \\ 2,3, Polymer \& Textile Engineering, Federal University of TeChnology, OWerri, Imo State, NigeriA
}

\author{
E-mail addresses: 1 onyekachi.egbuhuzor@unn.edu.ng, 2 icmadufor@gmail.com, \\ 3 simyn22@yahoo.co.uk, 4 olisaeloka.bokolo@unn.edu.ng
}

\begin{abstract}
Adsorption behaviour and corrosion rate of Sodium carboxymethyl cellulose on aluminium was studied. Different concentration levels of Sodium carboxymethyl cellulose (Na-CMC) solution were applied on several prepared and polished aluminium coupons for a corrosion experiment. These coupons were totally immersed in $100 \mathrm{ml}$ of $0.5 \mathrm{M}$ solution of Hydrochloric acid (HCI) in an open beaker placed in a water bath at varying temperatures for 2-8hrs respectively. At every specified temperature and time interval, the immersed coupon specimen was withdrawn from the test solution, washed, dried and reweighed. The weight loss being the difference in weight of the specimen before and after immersion in the water bath was recorded for every coupon sample. The effects of concentration, temperature and time on corrosion rate were studied and from the various plots, it was observed that increase in the concentration of the inhibitor decreases the corrosion rate. The study of the adsorption behaviour showed that Na-CMC was physically adsorbed on the aluminium coupons and obeyed Freundlich adsorption isotherm with an activation energy of $32 \mathrm{~K} .83 \mathrm{j} / \mathrm{mol}$ and heat of adsorption of $-18.21 \mathrm{Kj} / \mathrm{mol}$. The study also established a relationship between the corrosion rate, CR; concentration, $C_{;}$temperature, $T$; and time $t$, through a mathematical model: $C R=3.8^{-5 *} T^{1.1617}-0.00052 t^{0.6176}-0.0013 C^{0.8012}$, the proportion of variance explained $\left(R^{2}\right)=0.8658(86.58 \%)$, From the Results of the experiment and the model, $\mathrm{Na}-\mathrm{CMC}$ was found to be an active corrosion inhibitor of Aluminium in acidic environment.
\end{abstract}

Keywords: Adsorption, Aluminium, concentration, Corrosion Rate, Weight Loss

\section{INTRODUCTION}

Aluminium significantly plays a major role in engineering applications. Most engineering applications involve the use of one form of this metal or the other. Aluminium can be used in different applications to replace other materials like copper, steel, zinc, tin, stainless steel, titanium, wood, paper, concrete and composites [1]. This metal is used in the construction, automobile, in packaging, transport and marine industries. Other applications of aluminium include ladders, high pressure gas cylinders, sporting, furniture, road barriers and signs. Aluminium also plays major role in areas where light weight application is required like in the construction of towers needed to support the overhead cables for long distant electricity transmission, in aircraft constructions, missile bodies and satellite components etc [2].

Aluminium is applied in acidic, alkaline, neutral and rain water environments. These environments as mentioned by several researchers tend to react with the metal, changing its stable state and this state change causes failure. Failure of this engineering material causes devastating damage materially and in

* Corresponding author, tel: +234806 6348763 
some cases loss of life. One of the major causes of these failures include corrosion which is the deterioration of materials by chemical interaction with its environment [3]. The consequences of corrosion effect is so high that scientists, researchers and engineers look for ways of reducing the menacing effect of corrosion. Corrosion control is a process aimed at reducing the corrosion rate of a particular process to a tolerable level. The extent of control depends on the type and method of control used [4, $5,6]$. Corrosion can be controlled by the use of inhibitors, coatings and linings, material selection and cathodic protection.

Corrosion inhibitors are chemicals that are added to the controlled environment to reduce corrosivity of the environment. These inhibitors react with a metalic surface or the environment they are exposed to, giving the surface a certain level of protection $[7,8]$. Some of these polymeric inhibitors are biodegradable, cost effective, affordable and soluble in most media used. These can also be produced in large quantities for industrial and commercial use. Because of the harzardous effects of inorganic inhibitors and their health implications, there is the need for an organic material which is environmentally friendly, soluble in most media and at the same time cheap, affordable and readily available for use as protective soluble substances in coating or protecting these engineering materials from collapse [9]. These features made Sodium Carboxymethyl cellulose to be considered as good corrosion inhibitorr expecially when large scale proctection is needed. . Several authors like Obot, Solomon, Abdalla, Okafor, Umoren, Nwanonenyi etc. had investigated corrosion inhibition of aluminium using several inhibitors and under different environments $[7,8,10,11,13,25]$ but none had been able to establish a theoretical model between the corrosion rate and the independent variables like concentration, time and temperature. In this work, we investigated the corrosion inhibition of aluminium using Na-CMC and establish a relationship between corrosion rate, time temperature and inhibitor concentration through a theoretical model and the model results corroborated with that of the experiment.

\section{MATERIALS AND METHODS}

\subsection{Materials and Equipment:}

Materials used include AA1060 type of aluminium sourced from Alo Aluminium Ltd, Sodium carboxymethyl cellulose (produced by Qualikem Fine
Chem Pvt Ltd, Deihi, India and purchased from Lavans Chemicals Ltd, the company's distributor in Nigeria, emery papers, water bath, ethanol, acetone, distilled water, $\mathrm{HCl}$ (all analytical grades, sourced from GeoChem Ltd), desiccators, beakers, conical flask, timer, glass hook, and digital weighing balance.

\subsection{Metal Specimen Preparation}

Aluminium of $98 \%$ purity and AA1060 type was used and was sourced from Alo aluminium Ltd. Aluminium specimens were mechanically press-cut into coupons of dimensions $5 \times 3 \times 1 \mathrm{~mm}$. They were degreased by washing them in ethanol and then polished with emery paper. The metal samples were then rewashed in ethanol rinsed in acetone to dry and then stored in a desiccator before use.

\subsection{Experimental Method}

Weight loss measurement and theoretical modelling were used to determine the corrosion rate model and adsorption behaviour of Na-CMC on aluminium substrate.

\subsubsection{Weight Loss Measurement}

In this experiment, a prepared aluminium metal coupon was totally immersed in $100 \mathrm{ml}$ of $0.5 \mathrm{M} \mathrm{HCl}$ acid solution in a $120 \mathrm{ml}$ capacity glass beaker with the aid of plastic thread and glass rod. The beaker was placed in a water bath equilibrated at $35^{\circ} \mathrm{C}, 45^{\circ} \mathrm{C}$, $55^{\circ} \mathrm{C}$, and $65^{\circ} \mathrm{C}$ respectively [10]. At the end of stipulated time intervals $(2 \mathrm{~h}, 4 \mathrm{~h}, 6 \mathrm{~h}$ and $8 \mathrm{~h}$ respectively), the metal specimen was withdrawn from the test solution, washed, dried and reweighed [11]. The weight loss was determined as the difference in weight of the metal specimen before and after immersion in the test solution respectively. The test was conducted in triplicates to guarantee the reliability of the results and the average value of the weight loss $\left(\mathrm{W}_{1}\right)$ was taken. This procedure was repeated with varying concentrations of the inhibited solution. The following parameters determined from the results obtained are stated below;

Weight loss $\left(\mathrm{W}_{1}\right)$ : This is regarded as the material loss (reduction in size, shape and weight) due to degradation caused by corrosive agent. Mathematically, it can evaluated according to Equation (1):

Weight Loss $\left(W_{1}\right)=M_{1}-M_{2}$ 
where, $M_{1}=$ average weight in grams before immersion, $M_{2}=$ average weight in grams after immersion.

\subsubsection{Corrosion Rate ( $R$ )}

This is corrosion parameter that gives physical and visual information regarding the extent of penetration of the corrodent into the metal surface damage with respect to variation in time (3d). Usually, it is expressed in terms of loss of material thickness per unit time and engineers express it in microns per year $(\mu \mathrm{m} / \mathrm{y})$ or mils per year (mpy) or inches per year (ipy) millimetre per year $(\mathrm{mm} / \mathrm{yr})$ or milligrams/square decimetre or $\mathrm{mm}$ per year. Mathematically, it is expressed according Equation (2) stated below:

$$
\text { Corrosion Rate } \quad(R)=\left(\frac{87600 \Delta W}{\rho A t}\right)
$$

where, $\Delta \mathrm{W}=$ weight loss in gram, $\rho=$ density of the metal sample $\left(\mathrm{g} / \mathrm{cm}^{3}\right), \quad A=$ surface area of exposed metal sample $\left(\mathrm{cm}^{2}\right)$ and $\mathrm{t}=$ time of exposure (in hrs) [12].

\subsubsection{Degree of Surface Coverage $(\theta)$}

This corrosion parameter measures the extent or amount of corrosion site on the metal surface covered by the inhibitor. It is expressed using equation (3):

$$
\boldsymbol{\theta}=\left(\boldsymbol{R}_{\boldsymbol{b}}-\boldsymbol{R}_{\boldsymbol{i}}\right) / \boldsymbol{R}_{\boldsymbol{b}}
$$

where,, $\mathrm{Rb}_{\mathrm{b}}=$ corrosion rates of blank solution, $\mathrm{Ri}_{\mathrm{i}}=$ corrosion rates of inhibited solution.

\subsubsection{Adsorption Isotherm}

This is a parameter used to evaluate the mode of adsorption inhibition process. All the adsorptions isotherms were tested and plotted but only Freundlich adsorption isotherms has the highest $\mathrm{R}^{2}$ value and was used in this study. This isotherm is expressed as:

Fleundlich Isotherm $\log \theta=\log K_{a}+n \log C$

\subsection{Theoretical Modelling}

A mathematical model was designed during the corrosion inhibition investigation of the effects of Sodium Carboxymethyl Cellulose on aluminium coupons under acidic conditions using Phillip Sherrod's NLREG version 6.3 software. This model shows the relationship between Temperature $\mathbf{T}$, Time $\mathbf{t}$, concentration $\mathbf{C}$ and corrosion rate $\mathbf{C R}$, and was derived under the following conditions.

Total no of observations the experiment $=96$

No observations used in the NLREG $=90$
No of observations used to test the mathematical model $=6$ was used to validate the model.

The model has the following functions:

Corrosion Rate $(C R)=K_{1} \boldsymbol{T}^{a_{1}}+K_{2} \boldsymbol{T}^{\boldsymbol{a}_{2}}+K_{3} \boldsymbol{T}^{\boldsymbol{a}_{3}}$ (5) Where $k_{1}, k_{2}, k_{3}, a_{1}, a_{2}$ and $a_{3}$ are the parameters.

\section{RESULTS AND DISCUSSION}

\subsection{Weight Loss (Gravimetric) Measurements}

The dissolutio $\mathrm{n}$ and inhibition of aluminium coupon in $0.5 \mathrm{M} \mathrm{HCl}$ acid solution without and with different concentrations of $\mathrm{Na}-\mathrm{CMC}$ was investigated at varying temperatures $\left(35^{\circ} \mathrm{C}, 45^{\circ} \mathrm{C}, 55^{\circ} \mathrm{C}\right.$, and $65^{\circ} \mathrm{C}$ ) and time respectively using weight loss measurement technique. The results obtained were presented in Table 1. It can be seen from Table 1 that dissolution of aluminium in the test solution increased with time and temperature but the increment was much recorded in the blank specimen solution compared with the inhibited solutions [13]. It was observed that the relationship between the material loss and time at different inhibitor concentration and temperatures respectively is linear. In addition, it was seen that introduction of $\mathrm{Na}-\mathrm{CMC}$ in the blank solution reduced the corrosive nature of the system thereby regulating corrosion damage on the aluminium surface. Hence, this regulatory action of aluminium corrosion in $\mathrm{HCl}$ acid solution by Na-CMC was concentration dependent [14]. Critical evaluation of Table 1 revealed the influence of temperature on the corrosion behaviour of aluminium and inhibitive performance of $\mathrm{Na}-\mathrm{CMC}$ on aluminium exposed in $0.5 \mathrm{M} \mathrm{HCl}$ acid solution [15]. It was observed that increment in temperature boosted the damaging action of the corrosive agent (chloride ions) on the aluminium surface and even thwarted the protective effect enjoyed by Na-CMC at low temperature. The results obtained suggest that $\mathrm{Na}$ CMC possess inhibitive property and can serve as inhibitor for aluminium in $\mathrm{HCl}$ environment that requires low temperature exposure.

\subsection{Corrosion Rate}

The corrosion rate is closely related to weight loss in the sense that increasing the concentration of sodium carboxymethyl cellulose decreases the corrosion rate. Calculated values of corrosion rate against inhibitor concentration (Na-CMC) is shown in Table 2 and Figures 3 and 4. From Figures 3 and 4, corrosion rate is highest on the blank coupons when there was no sodium carboxymethyl cellulose added to the aluminium coupon specimen. 
Table 1 Calculated values of weight loss for Aluminium corrosion in $0.5 \mathrm{M} \mathrm{HCl}$ in the absence and presence of $\mathrm{Na}-\mathrm{CMC}$ at different time and temperatures.

\begin{tabular}{|c|c|c|c|c|c|}
\hline Time (h) & Conc $(\mathrm{g} / \mathrm{L})$ & & & & \\
\hline & & $35^{\circ} \mathrm{C}$ & $45^{\circ} \mathrm{C}$ & $55^{\circ} \mathrm{C}$ & $65^{\circ} \mathrm{C}$ \\
\hline \multirow[t]{6}{*}{2} & Blank & 0.050 & 0.085 & 0.131 & 0.156 \\
\hline & 0.200 & 0.025 & 0.058 & 0.099 & 0.142 \\
\hline & 0.400 & 0.020 & 0.048 & 0.092 & 0.135 \\
\hline & 0.600 & 0.017 & 0.042 & 0.086 & 0.124 \\
\hline & 0.800 & 0.014 & 0.035 & 0.073 & 0.104 \\
\hline & 1.000 & 0.007 & 0.020 & 0.051 & 0.073 \\
\hline \multirow[t]{6}{*}{4} & Blank & 0.071 & 0.107 & 0.146 & 0.229 \\
\hline & 0.200 & 0.038 & 0.066 & 0.112 & 0.194 \\
\hline & 0.400 & 0.032 & 0.060 & 0.102 & 0.188 \\
\hline & 0.600 & 0.028 & 0.055 & 0.098 & 0.173 \\
\hline & 0.800 & 0.025 & 0.048 & 0.084 & 0.152 \\
\hline & 1.000 & 0.015 & 0.035 & 0.063 & 0.115 \\
\hline \multirow[t]{6}{*}{6} & Blank & 0.081 & 0.125 & 0.168 & 0.310 \\
\hline & 0.200 & 0.050 & 0.079 & 0.129 & 0.270 \\
\hline & 0.400 & 0.043 & 0.072 & 0.125 & 0.258 \\
\hline & 0.600 & 0.039 & 0.069 & 0.101 & 0.240 \\
\hline & 0.800 & 0.035 & 0.061 & 0.085 & 0.225 \\
\hline & 1.000 & 0.021 & 0.040 & 0.072 & 0.175 \\
\hline \multirow[t]{6}{*}{8} & Blank & 0.090 & 0.140 & 0.180 & 0.394 \\
\hline & 0.200 & 0.065 & 0.098 & 0.134 & 0.345 \\
\hline & 0.400 & 0.058 & 0.091 & 0.125 & 0.314 \\
\hline & 0.600 & 0.053 & 0.082 & 0.115 & 0.285 \\
\hline & 0.800 & 0.048 & 0.075 & 0.107 & 0.270 \\
\hline & 1.000 & 0.030 & 0.052 & 0.085 & 0.225 \\
\hline
\end{tabular}

The corrosion rate gradually reduces as the concentration of the inhibitor (Na-CMC) is increased and it is lowest when the concentration of $1 \mathrm{~g} / \mathrm{L}$ solution of the inhibitor is applied. This is as a result of the increase in the coverage of the surface area of the aluminium coupons as the concentration of the inhibitor increases. The coverage would not allow the harsh acidic environment to attach aluminium sample by so doing reducing the effects and potency of the acid on attacking the metal. Sodium Carboxymethyl Cellulose affects both the weight loss, corrosion rate and inhibition efficiency in corrosion experiment.

\subsection{Temperature Effect on Corrosion of Aluminium}

Temperature increases the rate of mobility of molecules in corrosion experiment. As the temperature increases, the rate of disorder of the molecules also increases [16]. This disorder weakens the bonding of the inhibitor on the aluminium surface thereby exposing the coupons to attack by the acid [17]. Temperature changes in corrosion experiment play a vital role in the determination of the corrosion rate. At a particular concentration and fixed time interval, increase in the temperature of the environment increases the rate of corrosion of the aluminium coupons. From Table 2, it is evident that at $2 \mathrm{~h}$ time interval when the inhibitor concentration is $0.2 \mathrm{~g} / \mathrm{L}$, corrosion rate at the temperature of $35^{\circ} \mathrm{C}$ is $27.04 \mathrm{~mm} / \mathrm{yr}$.

The rate increased to $62.73 \mathrm{~mm} / \mathrm{yr}$ as the temperature reached $45^{\circ} \mathrm{C}$ and to $153.57 \mathrm{~mm} / \mathrm{yr}$ at $65^{\circ} \mathrm{C}$. Figures 5 and 6 show the relationship between corrosion rate and temperature and from the figures shown, it is observed that corrosion rate increased as the temperature increased.

This increase in temperatures breaks down the Van der Waal forces holding the molecules together with the aluminium interface and allow the Na-CMC to dissolve into solution.

This dissolution reduces the level of surface coverage of the coupon by the inhibitor and at the same time increasing the strength of acidic medium to attack the aluminium specimen coupon. This dissolution exposes 
the aluminium surfaces for attack by the acidic environment $(\mathrm{HCl})$. The rate of attack is more prominent as the temperature is increased and highest on the blank coupons as can be seen from the plot. Therefore, increase in the temperature of the environment increases the corrosion rate and vice versa. Increase in the temperature increases the corrosion rate as seen from the model equation and decreases as the temperature is lowered [18]. Therefore the corrosion rate of the model and that of the experiment follow the same trend in temperature relationship.

\subsection{Adsorption Studies on Corrosion of Aluminium}

Adsorption isotherm was used to evaluate the adsorption process due to the fact that adsorption is a surface phenomenon. Adsorption Isotherm is a graph that expresses the variation in the amount of molecules adsorbed by the adsorbent with concentration at constant temperature [19].

In order to determine which adsorption isotherm to adopt in the work, we use the values of the calculated surface coverage $(\theta)$ to fit in the already existing isotherms and the one with the highest $R^{2}$ values were used to determine the thermodynamic parameters governing the inhibitor adsorption. Freundlich Isotherm has the highest $R^{2}$ value and therefore fits in our experiment.

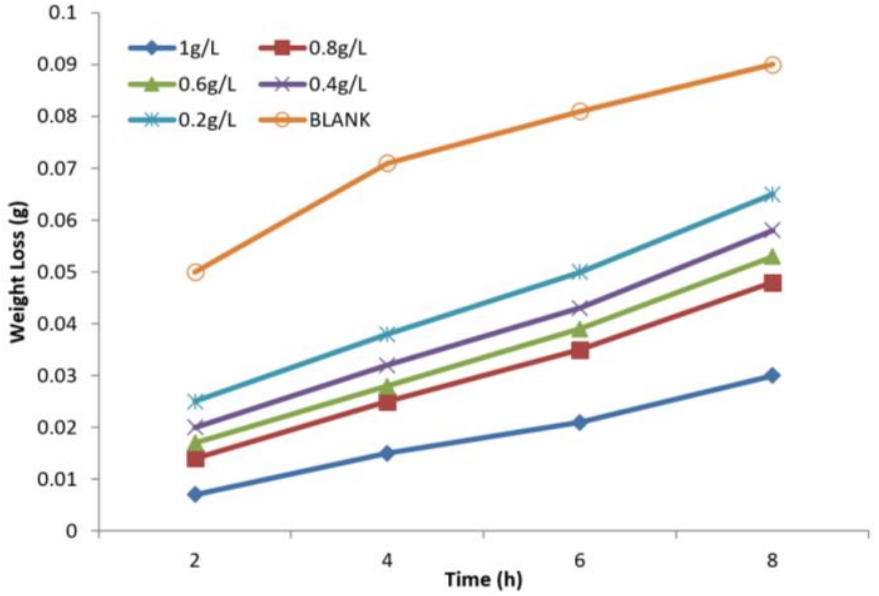

Fig.1: Variation of weight loss against time at varying concentration at $35^{\circ} \mathrm{C}$

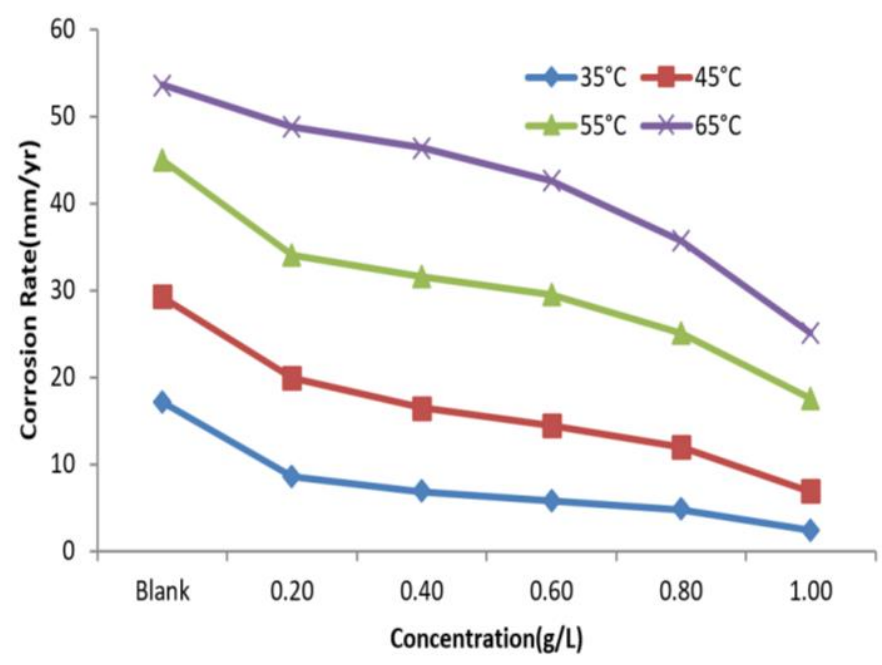

Fig 3: Variation of corrosion rate against concentration at varying temperatures for $2 \mathrm{~h}$

Table 2: Values of concentration against corrosion rate and Surface Coverage at different temperature and Time

\begin{tabular}{|c|c|c|c|c|c|c|c|c|c|}
\hline \multirow[t]{2}{*}{ Time(hrs) } & \multirow[t]{2}{*}{ Conc $(\mathrm{g} / \mathrm{L})$} & \multicolumn{4}{|c|}{ Corrosion rate $(\mathrm{mm} / \mathrm{yr})$} & \multicolumn{4}{|c|}{ Surface Coverage } \\
\hline & & $35^{\circ} \mathrm{C}$ & $45^{\circ} \mathrm{C}$ & $55^{\circ} \mathrm{C}$ & $65^{\circ} \mathrm{C}$ & $35^{\circ} \mathrm{C}$ & $45^{\circ} \mathrm{C}$ & $55^{\circ} \mathrm{C}$ & $65^{\circ} \mathrm{C}$ \\
\hline \multirow{6}{*}{2} & Blank & 17.19 & 29.22 & 45.03 & 53.62 & - & - & - & - \\
\hline & 0.2 & 8.59 & 19.94 & 34.03 & 48.81 & 0.50 & 0.32 & 0.24 & 0.09 \\
\hline & 0.4 & 6.87 & 16.50 & 31.62 & 46.41 & 0.60 & 0.44 & 0.30 & 0.13 \\
\hline & 0.6 & 5.84 & 14.44 & 29.56 & 42.62 & 0.66 & 0.51 & 0.34 & 0.21 \\
\hline & 0.8 & 4.81 & 12.03 & 25.09 & 35.75 & 0.72 & 0.59 & 0.44 & 0.33 \\
\hline & 1.0 & 2.41 & 6.87 & 17.53 & 25.09 & 0.86 & 0.76 & 0.61 & 0.53 \\
\hline \multirow{6}{*}{4} & Blank & 12.20 & 18.39 & 25.09 & 39.36 & - & - & - & - \\
\hline & 0.20 & 6.53 & 11.34 & 19.25 & 33.34 & 0.46 & 0.38 & 0.23 & 0.15 \\
\hline & 0.40 & 5.50 & 10.31 & 17.53 & 32.31 & 0.55 & 0.44 & 0.30 & 0.18 \\
\hline & 0.60 & 4.81 & 9.45 & 16.84 & 29.73 & 0.61 & 0.49 & 0.33 & 0.24 \\
\hline & 0.80 & 4.30 & 8.25 & 14.44 & 26.12 & 0.65 & 0.55 & 0.42 & 0.34 \\
\hline & 1.00 & 2.58 & 6.02 & 10.83 & 19.77 & 0.79 & 0.67 & 0.57 & 0.50 \\
\hline \multirow{3}{*}{6} & Blank & 9.28 & 14.32 & 19.25 & 35.52 & - & - & - & - \\
\hline & 0.20 & 5.73 & 9.05 & 14.78 & 30.94 & 0.38 & 0.37 & 0.23 & 0.13 \\
\hline & 0.40 & 4.93 & 8.25 & 14.32 & 29.56 & 0.47 & 0.42 & 0.27 & 0.17 \\
\hline
\end{tabular}




\begin{tabular}{llllllllll}
\hline Time(hrs) & Conc(g/L) & \multicolumn{9}{l}{ Corrosion rate(mm/yr) } & \multicolumn{7}{l}{ Surface Coverage } \\
\hline \multirow{6}{*}{} & 0.60 & 4.47 & 7.91 & 11.57 & 27.50 & 0.52 & 0.45 & 0.40 & 0.23 \\
& 0.80 & 4.01 & 6.99 & 9.74 & 25.78 & 0.57 & 0.51 & 0.49 & 0.27 \\
& 1.00 & 2.41 & 4.58 & 8.25 & 20.05 & 0.74 & 0.68 & 0.57 & 0.44 \\
& Blank & 7.73 & 12.03 & 15.47 & 33.86 & - & - & - & - \\
& 0.20 & 5.59 & 8.42 & 11.52 & 29.65 & 0.32 & 0.30 & 0.25 & 0.12 \\
& 0.40 & 4.98 & 7.82 & 10.74 & 26.98 & 0.36 & 0.35 & 0.31 & 0.20 \\
& 0.60 & 4.55 & 7.05 & 9.88 & 24.49 & 0.41 & 0.42 & 0.36 & 0.27 \\
& 0.80 & 4.12 & 6.45 & 9.20 & 23.20 & 0.47 & 0.46 & 0.41 & 0.31 \\
& 1.00 & 2.58 & 4.47 & 7.30 & 19.34 & 0.67 & 0.63 & 0.53 & 0.43
\end{tabular}

Table 3 shows the values of inhibitor concentration $(\mathrm{g} / \mathrm{L})$, temperature and degree of surface coverage used to find the isotherm the experiment followed.

Freundlich Isotherm $\log \theta=\log K_{a}+n \log C$

Where $K_{a}$ is the equilibrium constant of the adsorption process, $C$ the inhibitor concentration, $\theta$ is the surface coverage. It is a known fact that $\mathrm{K}_{\mathrm{a}}$ is the strength between adsorbate and adsorbent [20]. The best fitted straight line was obtained from the plot of $\log \theta$ against $\log C$, that is the Freundlich Isotherm with an $\mathrm{R}^{2}$ value of $99.88 \%$ at temperature $65^{\circ} \mathrm{C}$. Therefore, this corrosion test we carried out obeyed Freundlich adsorption isotherm.

\section{Freundlich Adsorption Isotherm}

The Freundlich equation or Freundlich adsorption isotherm is an empirical relation between the concentration of a solute on the surface of an adsorbent to the concentration of the solute in the inhibitor with which it is in contact [21]. This shows a plot of the $\log$ of the surface coverage $(\log \theta)$ against the log of concentration (Log C). Table 4 shows the values of $\log C$ and the corresponding values of $\log \theta$ at different temperatures. The plot of $\log \theta$ against $\log C$ gives the slope as $n$ and the intercept as $\log K$. The $R^{2}$ values of the plot of $\log \theta$ against $\log C$ at various temperatures are shown in Fig. 7. The highest $\mathrm{R}^{2}$ of $99.85 \%$ was recorded at a temperature of $65^{\circ} \mathrm{C}$.

\subsection{Thermodynamic Considerations of Corrosion Aluminium 3.5.1 Activation Energy}

In corrosion studies, the corrosion rate is related to temperature by the Arrhenius equation 6 . This is the minimum amount of energy required to break the van de Waal forces holding the molecules of the inhibitor out of the surface of the aluminium before corrosion can take place [22].

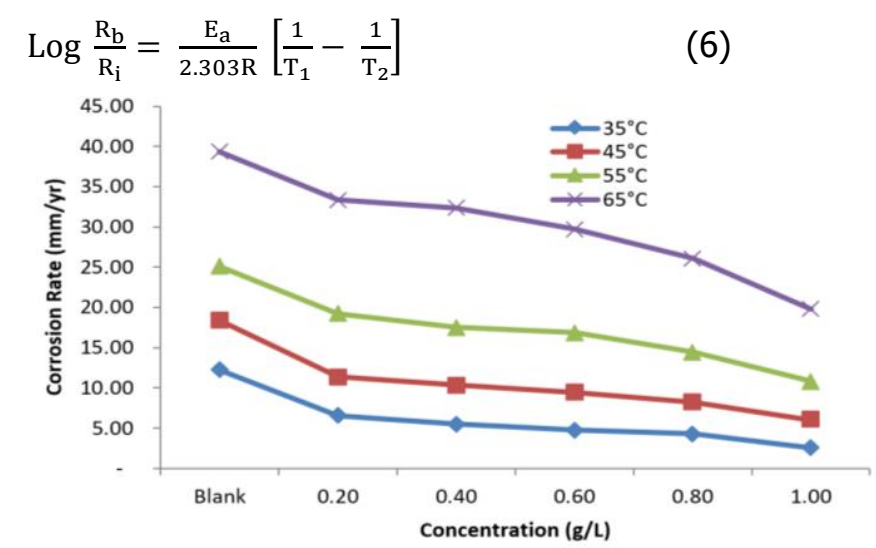

Fig 4 Variation of corrosion rate against concentration at varying temperatures for $4 \mathrm{~h}$

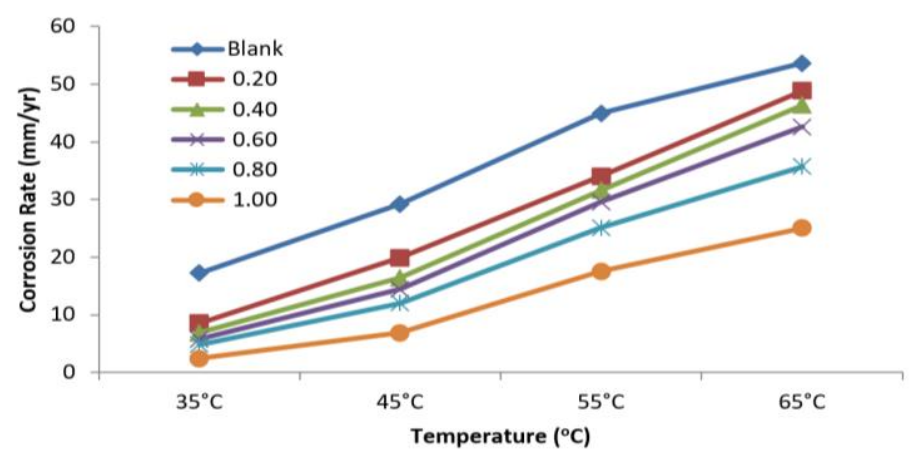

Fig 5 Variation of corrosion rate against temperature at varying concentration for $2 h$.

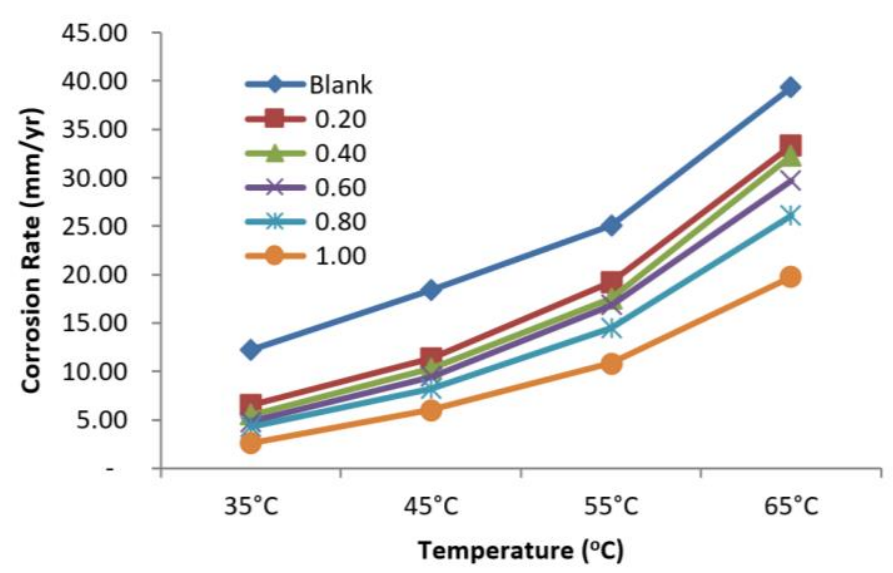

Fig. 6 Variation of corrosion rate against temperature at varying concentration for $4 h$. 
Table 3 Inhibitor concentration and calculated surface coverage

\begin{tabular}{lllll}
\hline concentration $(\mathrm{g} / \mathrm{L})$ & \multicolumn{5}{c}{ Surface Coverage } \\
\hline & $35^{\circ} \mathrm{C}$ & $45^{\circ} \mathrm{C}$ & $55^{\circ} \mathrm{C}$ & $65^{\circ} \mathrm{C}$ \\
0.0000 & 0.0000 & 0.0000 & 0.0000 & 0.0000 \\
0.2000 & 0.5000 & 0.3176 & 0.2443 & 0.0898 \\
0.4000 & 0.6000 & 0.4353 & 0.2977 & 0.1346 \\
0.8000 & 0.6600 & 0.5059 & 0.3435 & 0.2051 \\
1.0000 & 0.7200 & 0.5882 & 0.4427 & 0.3333 \\
\hline
\end{tabular}

Table 4 Calculated values of $\log C$ vs $\log \theta$

\begin{tabular}{ccccc}
\hline $\log \mathrm{C}(\mathrm{g} / \mathrm{L})$ & \multicolumn{5}{c}{$\log \theta$} & $65^{\circ} \mathrm{C}$ & $65^{\circ} \mathrm{C}$ \\
\hline & $35^{\circ} \mathrm{C}$ & $45^{\circ} \mathrm{C}$ & -0.6121 & -1.0467 \\
-0.699 & -0.301 & -0.4981 & -0.5262 & -0.871 \\
-0.3979 & -0.2218 & -0.3612 & -0.4641 & -0.688 \\
-0.2218 & -0.1805 & -0.2959 & -0.3539 & -0.4772 \\
-0.0969 & -0.1427 & -0.2305 & -0.2142 & -0.274 \\
0 & -0.0655 & -0.1165 & & \\
\hline
\end{tabular}

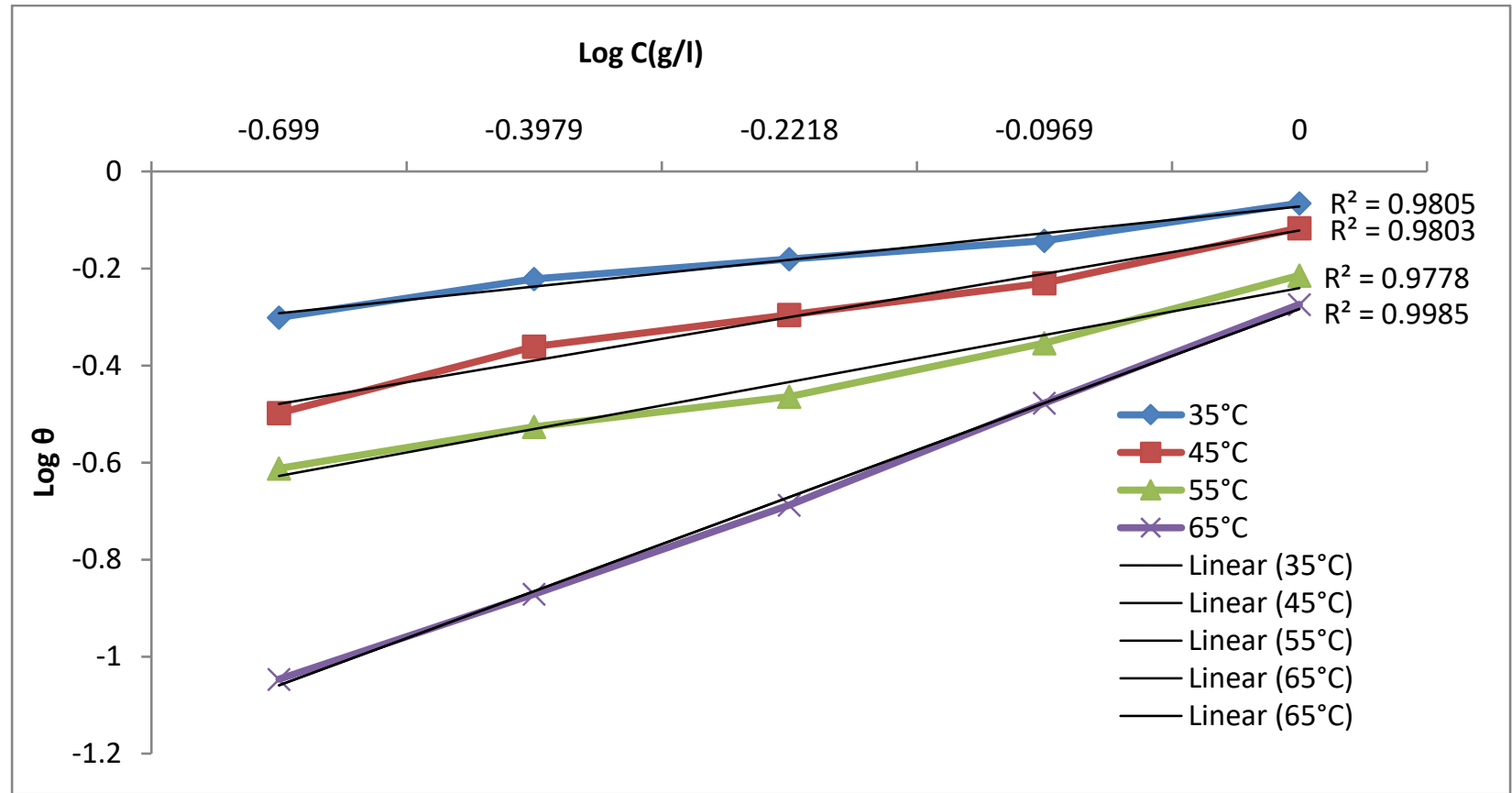

Fig. 7 Freundlich adsorption isotherm plot of $\log \theta$ versus $\log C$ for sodium carboxymethyl cellulose at different temperatures.

In Equation (6) $R_{b}$ is the corrosion rate of the blank coupon and $\mathrm{R}_{\mathrm{i}}$ is the corrosion rate of the inhibitor determined from the weight loss measurement, Ea is the apparent activation energy, $R$ the molar gas constant $\left(8.314 \mathrm{~J} \mathrm{~K}^{-1} \mathrm{~mol}^{-1}\right.$ ) and $\mathrm{T}_{1}$ and $\mathrm{T}_{2}$ is the absolute temperatures of the blank coupon and the inhibitor respectively [23]. The calculated values of the apparent activation energy, Ea is shown in Table 5 below.

From Table 5, the calculated values of Ea in the presence of different concentrations of the inhibitor were higher than that in its absence. This is because of the formation of an adsorptive film of a physical electrostatic character of sodium carboxymethyl cellulose and this adsorbed $\mathrm{Na}-\mathrm{CMC}$ created a physical barrier against attack of the aluminium by the acidic medium. The activation energy increases as the inhibitor concentration increases. This is because of increase of adsorptive films on the surface of the aluminium coupons as the concentration increases [24]. 
Table 5: Calculated values of activation energy $\left(E_{a}\right)$ and heat of adsorption ( $\left.Q_{a d s}\right)$ for aluminium in $0.5 \mathrm{M} \mathrm{HCl}$ for the different concentrations of Na-CMC for 2 hrs.

\begin{tabular}{lll}
\hline $\begin{array}{l}\text { Concentratration } \\
(\mathrm{g} / \mathrm{L}\end{array}$ & $\begin{array}{l}\text { Activation energy }(\mathrm{Ea})(\mathrm{kJ} / \mathrm{mol}) \\
35^{\circ} \mathrm{C}-65^{\circ} \mathrm{C}\end{array}$ & $\begin{array}{l}\text { Heat of adsorption (Qads) } \\
(\mathrm{kJ} / \mathrm{mol}) 35^{\circ} \mathrm{C}-65^{\circ} \mathrm{C}\end{array}$ \\
\hline Blank & 32.83 & \\
0.2 & 50.13 & -18.21 \\
0.4 & 55.12 & -17.06 \\
0.6 & 57.35 & -16.58 \\
0.8 & 57.88 & -14.05 \\
1.0 & 67.60 & -12.37 \\
\hline
\end{tabular}

From theory, if the activation energy of blank coupon $\left(E_{a b}\right)$ is less than the activation energy of the inhibitor $\left(E_{\mathrm{ai}}\right)$, then, the mechanism is physiosorption. From Table 5 below, the adsorption of Na-CMC is typical physiosorption because $E_{a b}$ is less than $E_{a i}$.

\subsubsection{Heat of Adsorption:}

Heat of adsorption is the heat evolved when a given amount of the inhibitor is adsorbed on the surface of the aluminium coupon. An estimate of heat of adsorption was obtained from the trend of surface coverage with temperature as shown in equation 7 [25].

$$
\mathrm{Q}_{\mathrm{ads}}=2.303 \mathrm{R}\left[\log \left(\frac{\theta_{2}}{1-\theta_{2}}\right)-\log \left(\frac{\theta_{1}}{1-\theta_{1}}\right)\right] \times \frac{\mathrm{T}_{1} \mathrm{~T}_{2}}{\mathrm{~T}_{2}-\mathrm{T}_{1}}(7)
$$

The calculated value of the heat of adsorption of $\mathrm{Na}-$ CMC on the aluminium coupon is shown in table 5 . More importantly, the heat of adsorption is used to confirm if the reaction is chemisorption or physiosorption. It is believed that the mechanism is physiosorption if heat of adsorption is less negative than $-40 \mathrm{kJmol}^{-1}$ and chemisorption, if enthalpy of adsorption is more negative than $-100 \mathrm{kJmol}^{-1}$ [26]. The heat of adsorption in this our experiment is less than $-40 \mathrm{kjmol}^{-1}$, therefore the adsorption of sodium carboxymethyl cellulose on the aluminium coupon is typical physiosorption.

\subsection{Corrosion Rate Model}

Corrosion modelling expresses the relationship between the independent variables; concentration, temperature and time and the dependent variable corrosion rate in a mathematical format. The model equation shows the relationship between corrosion rate, concentration, temperature and time interval of the experiment. $R^{2}$ values and $\operatorname{Prob}(t)$ are statistical values used to validate the overall significance of the model produced. Also, the data from the experiment were substituted in the model and were used to validate the model equation. The mathematical model equation developed in this our work relates the
Corrosion Rate (CR) with the variables used in the NLREG model. The independent variables are temperature $(T)$, Concentration (C) of the inhibitor used, time (t)intervals used in the corrosion experiment while the dependent variable is Corrosion Rate (CR). The relationship between the variables was presented with a model equation as given in equation 5.

Corrosion rate $(C R)=K_{1} \boldsymbol{T}^{a_{1}}+K_{2} \boldsymbol{T}^{\boldsymbol{a}_{2}}+K_{3} \boldsymbol{T}^{\boldsymbol{a}_{3}}$

Where $\mathrm{k}_{1}, \mathrm{k}_{2}, \mathrm{k}_{3}, \mathrm{a}_{1}, \mathrm{a}_{2}$ and $\mathrm{a}_{3}$ are parameters.

The result of the parameters/constants obtained from the plot of the variable functions using the Non-linear regression analysis software are presented in Table 6 Substituting the values of the parameters of Table 6 in equation (5), gave equation

$$
\begin{gathered}
C R=3.8525^{-5} T^{1.1617}-0.00052 t^{0.6176} \\
-0.0013 C^{0.8012}
\end{gathered}
$$

Therefore, equation (8) is the theoretical model derived from the experiment and this has a proportion of variance explained $\left(R^{2}\right)=0.8658(86.58 \%)$. This $R$-squared $\left(R^{2}\right)$ value measures the strength of the relationship between the model and the dependent variable on a convenient $0-100 \%$ scale. If the function perfectly predicts the observed data, the value of this statistic will be $1.00(100 \%)$. If the function does no better a job of predicting the dependent variable than using the mean, the value will be 0.00 . Our model gave an $\mathrm{R}^{2}$ value of $86.58 \%$ which significantly showed that the strength of the relationship between the experimental variables; Corrosion Rate $(R)$, Temperature $(T)$, Time $(t)$, and Concentration (C) as computed in the NLReg model software is very high.

Table 7 and Fig. 8 show the comparison between the experimental and model data. It is observed that increase in temperature increases corrosion rate for both the experiment and model. Therefore the model confirms the results of experimental work. In fig. 8, the two graphs seem to align together. 
Table 7 Comparison of the graph of Corrosion Rate from both the Model and the Experiment.

\begin{tabular}{lllll}
\hline Temp $\left({ }^{\circ} \mathrm{C}\right)$ & Time $(\mathrm{hrs})$ & Conc $(\mathrm{g} / \mathrm{L})$ & \multicolumn{3}{l}{ Corrosion Rate $(\mathrm{mm} / \mathrm{yr})$} \\
\hline & & & Model & Experiment \\
35 & 2 & 0.8 & 0.000549999 & 0.000466667 \\
35 & 6 & 1 & 0.000425211 & 0.000233333 \\
45 & 4 & 0.4 & 0.00138866 & 0.001 \\
45 & 8 & 0.2 & 0.000997357 & 0.000816667 \\
55 & 2 & 0.6 & 0.00242188 & 0.002866667 \\
55 & 6 & 0.4 & 0.00214319 & 0.001388889 \\
65 & 4 & 0.2 & 0.00335657 & 0.003233333 \\
65 & 8 & 0.8 & 0.002000024 & 0.00225 \\
\hline
\end{tabular}

The slight deviation may be caused as a result of environmental factors which affect only the experiment as it is being conducted. The environmental factors include: Human error of omission and commission as readings were being taken, power and other factors which affect the experiment and this brought about the slight deviation from the model as can be seen in Fig 8

Table 6 Calculated value of Corrosion rate parameters used from the model.

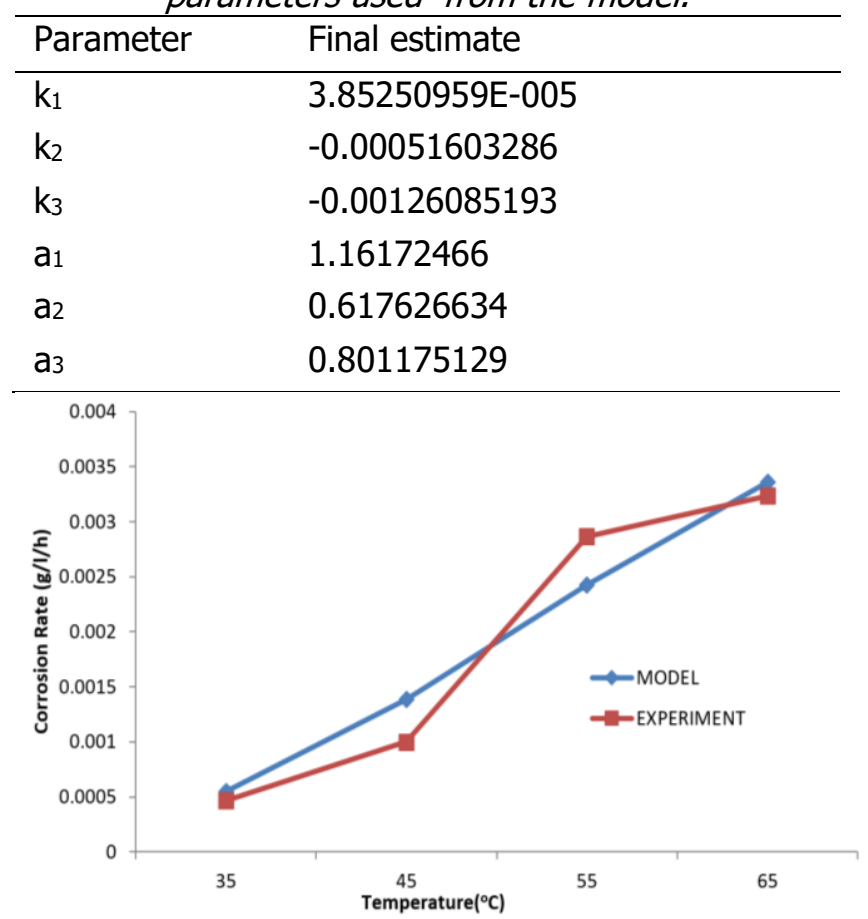

Fig. 8: Variation of Corrosion Rate Against Temperature from the model \& that of the experiment.

\section{CONCLUSION}

Sodium Carboxymethyl cellulose is an active corrosion inhibitor for Aluminium on acidic environment. Increasing the concentration of the inhibitor deceases the corrosion rate and vice versa.

Also, increasing the temperature of the operating environment increases the corrosion rate.
The relationship between the concentration of the inhibitor, the temperature of the operating environment, the exposure time and the corrosion rate is represented with a model:

$$
\begin{gathered}
C R=3.8525^{-5} T^{1.1617}-0.00052 t^{0.6176} \\
-0.0013 C^{0.8012}
\end{gathered}
$$

the proportion of variance explained $\left(R^{2}\right)=0.8658$ $(86.58 \%)$ and the prob(t) is 0.000001 .

The results of thermodynamic parameters indicated that the adsorption of $\mathrm{Na}-\mathrm{CMC}$ on the aluminium surface obeyed Freundlich adsorption isotherm and was a typical of physiosorption.

\section{REFERENCES}

[1] T. Adrian, M. Borzan, A. Popan, D. Fraţilă, A. Rus, and C. Nedezki. "Researches Regarding the Influence of Cutting Regime on Processed Surface in Aluminum Alloys Turning Process", Applied Mechanics and Materials, Vol 808, page 15-20, 2015.

[2] Aalco Metal Ltd. 'In Introduction to Aluminium and its alloys' www.aalco.co.uk. Accessed on March 2019.

[3] G. C. Dariva and A. F. Galio. 'Corrosion Inhibitors Principles, Mechanisms and Applications' in Developments in Corrosion Protection. licensee InTechopen, vol 16, pg355-379, 2014.

[4] ASM International. 'Corrosion: Understanding the Basics, The Effects and Economic Impact of Corrosion'. American Technical Publishers Ltd. www.asminternational.org. Accessed on February, 2019.

[5] H.H. Uhlig and R.W. Revie. 'Corrosion and Corrosion Control, 3rd ed., John Wiley \& Sons, New York, 1985.

[6] Mohammad-Abolghasemi. 'Materials Effects \& Economic impact of Corrosion', NACE International, 2016.

[7] I.B. Obot, N.O. Obi-Egbedi. 'Adsorption properties and inhibition of mild steel corrosion in sulphuric 
acid solution by ketoconazole: Experimental and theoretical investigation'. Corrosion Science, Vol 52, pp198-204, 2010.

[8] M. Abdallah, I. Zaafarany, A. Fawzy, M.A. Radwan and E. Abdfattah. 'Inhibition of Aluminum Corrosion in Hydrochloric Acid by Cellulose and Chitosan' Journal of Am. Science, Vol 9, no 4, pp 580-586, 2013.

[9] D. E. Arthur, A. Jonathan, P. O. Ameh and C. Anya. 'A review on the assessment of polymeric materials used as corrosion inhibitor of metals and alloys'. International Journal of Industrial Chemistry, vol 4, no 2, pp2-9, 2013.

[10] S. C. Nwanonenyi, H. C. Obasi, I. C. Chukwujike, M. A. Chidiebere, E. E. Oguzie. "Inhibition of Carbon Steel Corrosion in $1 \mathrm{M} \mathrm{H}_{2} \mathrm{SO}_{4}$ Using Soy Polymer and Polyvinylpyrrolidone", Chemistry Africa, vol 2, pp277-289, 2018.

[11] S. A. Umoren, M. M. Solomon, I. I. Udosoro and A. P. Udoh. "Synergistic and antagonistic effects between halide ions and carboxymethyl cellulose for the corrosion inhibition of mild steel in sulphuric acid solution", Springer Cellulose, vol 17, no. 3, pp635648, 2010.

[12] Simeon C. Nwanonenyi, Innocent C. Madufor, Iheoma C. Chukwujike, Vicent C. Arinze. "Experimental and Theoretical Studies of Inhibitive Behaviour of Millet Starch on the Corrosion of Aluminium in Sulphuric Acid Environment", International Journal of Engineering and Technologies, vol 8, pp 1-13, 2016.

[13] Salah, E.,Abdallah,M., Kamar,E., \& El-Etre,A. Y. Corrosion inhibition of aluminum and aluminum silicon alloys in sodium hydroxide solutions by methyl cellulose, Environ. Sci., Vol 6, number 3, page 892-901, 2015.

[13] M. M. Solomon, S. A. Umoren. "Enhanced corrosion inhibition effect of polypropylene glycol the presence of iodide ions at mild steel/sulphuric acid interface", Journal of Environmental Chemical Engineering, vol 3, no. 3, pp1812-1826, 2015.

[14] S.A. Umoren, I.B. Obot, E.E. Ebenso, N.O. ObiEgbedi. "The Inhibition of aluminium corrosion in hydrochloric acid solution by exudate gum from Raphia hookeri", Desalination, vol 247, no.1-3, pp561-572, 2009.

[15] S.M. Sayyah, S.S.Abd El-Rehim, M.M. El-Deeb, S.M. Mohame. "The Corrosion Inhibition of Aluminium by Some of 3- alkyloxyaniline Monomeric Surfactants and Their Analogues Polymers in $0.5 \mathrm{M} \mathrm{HCl}$ Solution", InTech, (2014).

[16] N. Hassan, S. M. Ali, A. Ebrahim, H. El-Adwy. " Performance evaluation and optimization of extract as green corrosion inhibitor for mild steel in acidic medium ", Materials Research Express, vol 2, no 7, pp3997-4008, 2019.

[17] S.A. Umoren, U.M. Eduok, M.M. Solomon. "Effect of polyvinylpyrrolidone - polyethylene glycol blends on the corrosion inhibition of aluminium in $\mathrm{HCl}$ solution", Pigment \& Resin Technology, vol 43, no 5, pp299-313, 2014.

[18] D. P. Sahaya Sudherson, P. P. Anandkumar, G. R. Jinu, K A. Balasubramanian, S. C. Vettivel. "Experimental investigation on corrosion behavior of friction surfaced mild steel with aluminum alloy 5083- Cadmium composite", Materials Research Express, vol 6, 2019, pp1-10.

[19] Encyclopedia of Membranes", Springer Nature, (2016).

[20] S. A. Umoren, O. Ogbobe, P. C. Okafor, E. E. Ebenso. "Polyethylene glycol and polyvinyl alcohol as corrosion inhibitors for aluminium in acidic medium", Journal of Applied Polymer Science, vol 105, pp3363-3370, 2007.

[21] S. Abd El Wanees, A. Diab, O. Azazy, and M. Abd El Azim. "Inhibition Effect of N-(Pyridin-2-ylCarbamothioyl) Benzamide on the Corrosion of CSteel in Sulfuric Acid Solutions", Journal of Dispersion Science and Technology, vol 35, no 11, pp1571-1580, 2014.

[22] R. Puthalath, A. O. Surendranathan, C. S. NarayanaMurthy. "Protective Performance of Furfuryl Alcohol on $13 \mathrm{Cr}$ L80 Steel against Corrosion in Hydrochloric Acid Solution", Industrial \& Engineering Chemistry Research, vol 53, no 1, pp23-30, 2014.

[23] M. A. Amin, M.A. Almed, H.A. Arida, M.A. Basaran, F. Kamdemirli and M. Saracoglu. "Monitoring corrosion and corrosion control of iron in $\mathrm{HCl}$ by non-ionic surfactants of the TRITON-X series - Part II. Temperature effect, activation energies and thermodynamics of adsorption", Corrosion Science, vol 53, pp1895-1909, 2011.

[24] I. B. Obot and N. O. Obi-Egbede. "Adsorption properties and inhibition of mild steel corrosion in sulphuric acid solution by ketoconazole: Experimental and theoretical investigation", Corrosion Science, vol 52, pp198-204, 2010.

[25] P.C. Okafor and E.A. Apebende. " Corrosion inhibition characteristics of , and extracts on mild steel in H SO solutions ", Pigment \& Resin Technology, vol 43, no 6, pp357-364, 2014.

[26] M. N. EL-Haddad. "Hydroxyethylcellulose used as an eco-friendly inhibitor for 1018 c-steel corrosion in $3.5 \% \mathrm{NaCl}$ solution", Carbohydrate Polymers, vol 32, n0 6, pp1-37, 2014.. 